\title{
Characterization and application of FRCM as a strengthening material for shear-critical RC beams
}

\author{
Adel Younis ${ }^{1 *}$, and Usama Ebead $^{2}$ \\ ${ }^{1} \mathrm{PhD}$ candidate, Department of Civil and Architectural Engineering, College of Engineering, Qatar University, Doha, Qatar \\ ${ }^{2}$ Professor, Department of Civil and Architectural Engineering, College of Engineering, Qatar University, Doha, Qatar
}

\begin{abstract}
This paper investigates the effectiveness of fabric reinforced cementitious matrix (FRCM) systems in shear-strengthening of reinforced concrete beams. Three types of FRCM systems were considered, namely, polyparaphenylene benzobisoxazole (PBO)-FRCM, Carbon-FRCM, and GlassFRCM. At first, tensile characterization test was performed on 15 FRCM coupons with the aim of identifying the tensile properties of the FRCM systems adopted. After that, seven shear-critical RC beams were tested under three-point loading, with the consideration of two test parameters: (a) FRCM material (glass/carbon/PBO); and (b) strengthening configuration (full/intermittent). The study results revealed the use of FRCM as a strengthening material to achieve a considerable improvement in the structural capacity of shear-critical RC beams. The average gain in the shear capacity of the FRCMstrengthened beams was $57 \%$. The beam specimens strengthened with carbon-FRCM showed the highest improvement as compared to those strengthened with glass- and PBO-FRCM systems. As intuitively expected, the shear capacity improvement achieved with the full-length strengthening systems was generally higher than that with the intermittent counterparts.
\end{abstract}

\section{Introduction}

Structural damage is normally encountered in reinforced concrete (RC) structures subject to harsh environment or unexpected extra loads [1]. Consequently, different strengthening techniques of RC members were proposed to enhance their structural capacity such as ferrocement [2] and fibre reinforced polymer (FRP) [3-8]. Latterly, fabric reinforced cementitous matrix (FRCM) strengthening systems have emerged as a viable solution for structural rehabilitation and repair. FRCM consists of dry fibres embedded in an inorganic matrix, which is externally applied on the surface for the aim of strengthening RC and masonry structures $[9,10]$.

FRCM systems have been successfully applied in the previous research for strengthening $\mathrm{RC}$ members such as slabs [11], columns [12-14], and beams critical in flexure $[15,16]$ or in shear [17-20]. In these studies, a noticeable improvement was generally reported in the loading capacity of the FRCM-strengthened members as compared to that of the non-strengthened benchmarks. Nonetheless, it is well-agreed that a proper understanding of the tensile characteristics of the FRCM composite is required to complete the structural design or numerical modeling of the FRCM strengthening system [21-23].

In view of this, the current paper has a two-fold objective: (a) to investigate the effectiveness of FRCM systems in strengthening of shear-critical RC beams; (b) to enrich the literature with contextual data pertinent to the tensile characteristics of commercially available
FRCM systems, which can be used for future applications in structural rehabilitation and repair. In this effort, the authors have considered three types of FRCM systems: Glass (G)-FRCM, Carbon (C)-FRCM, and polyparaphenylene benzobisoxazole (PBO)-FRCM. At first, tensile characterization test was performed on 15 FRCM test coupons to obtain the tensile properties of the utilized FRCM systems. After that, a total of seven RC beams critical in shear were tested under three-point loading to assess the efficacy of FRCM strengthening systems, while considering the FRCM type and strengthening configuration as test variables.

In the beginning, the experimental program will be explained in terms of materials description, test specimens, and test setup. After that, results and observations of this experimental study will be presented and discussed, mainly for the tensile characteristics of the FRCM systems as well as the structural performance of the strengthened RC beams.

\section{Experimental methodology}

\subsection{Materials}

Ready-mixed concrete with a 30-MPa average 28-day strength was used for casting the beam specimens. Beam specimens were reinforced with bars of grade 500B (BS 4449:2005 [24]). The average mechanical properties of the steel reinforcement based on tested samples are 595

* Corresponding author: adel.younis@qu.edu.qa 
$\mathrm{MPa}$ for the yield stress, $0.266 \%$ for the yield strain, and $224 \mathrm{GPa}$ for the modulus of elasticity.

Three types of FRCM systems were considered, which are: Glass-FRCM [25], Carbon-FRCM [26], and PBOFRCM [27]. To prepare the FRCM composite, the textile was embedded in its corresponding mortar in accordance with the manufacturers' recommendations. The amount of mixing water needed per $25 \mathrm{~kg}$ of mortar was 5 litres for the Glass-FRCM and 7 litres for the Carbon- and PBOFRCM systems. The mechanical properties for each textile type as provided by the manufacturers are listed in Table 1, including the textile area per unit width $\left(A_{f}\right)$, ultimate strain $\left(\varepsilon_{u}\right)$, elastic modulus $(E)$, and tensile strength $\left(\sigma_{f u}\right)$, along with the compressive strength of their associated mortars $\left(f_{c}\right)$.

Table 1. Textile and mortar properties for the FRCM systems.

\begin{tabular}{|c|c|c|c|c|c|}
\hline $\begin{array}{c}\text { Textile } \\
\text { type }\end{array}$ & $\begin{array}{c}\boldsymbol{A}_{\boldsymbol{f}} \\
\left(\mathbf{m m}^{\mathbf{2}} \mathbf{m m}\right)\end{array}$ & $\begin{array}{c}\mathbf{E} \\
\mathbf{( G P a )}\end{array}$ & $\begin{array}{c}\boldsymbol{\sigma}_{\boldsymbol{f u}} \\
(\mathbf{G P a})\end{array}$ & $\begin{array}{c}\boldsymbol{\varepsilon}_{\boldsymbol{u}} \\
\mathbf{( \% )}\end{array}$ & $\begin{array}{c}\boldsymbol{f}_{\boldsymbol{c}} \\
(\mathbf{M P a})\end{array}$ \\
\hline PBO & 0.045 & 270 & 5.80 & 2.15 & 30 \\
\hline Carbon & 0.047 & 240 & 4.80 & 1.80 & 20 \\
\hline Glass & 0.047 & 80 & 2.60 & 3.25 & 40 \\
\hline
\end{tabular}

\subsection{Test specimens}

\subsubsection{FRCM tensile coupons}

In accordance with AC434 [28], five tensile coupons were prepared for each FRCM system. A panel of $410 \mathrm{~mm}$ in length, $250 \mathrm{~mm}$ in width, and $10 \mathrm{~mm}$ in thickness was first cast on a flat wooden mould. After being cured for 28 days, each panel was cut to five number of 410-mm long, 50-mm wide, and 10-mm thick coupons. Each FRCM tensile coupon encompassed a single textile layer, of which the longitudinal direction was parallel to the coupon's length.

\subsubsection{RC beam specimens}

Seven 2100-mm long, 150-mm wide, and 330-mm deep reinforced concrete beams were tested. Bars of $16 \mathrm{~mm}$ in diameter were used as flexural reinforcement, while 8$\mathrm{mm}$ diameter stirrups spaced at $100 \mathrm{~mm}$ were used as shear reinforcement in the non-critical regime. The beam specimens had no stirrups within the 550-mm long critical span as illustrated in Figure 1. One of the beam specimens was kept non-strengthened as a benchmark, while the rest were FRCM-strengthened within the critical shear span with different types and configurations (Figure 1). A 34$\mathrm{mm}$ clear concrete cover was typically considered, leading to an effective depth of $280 \mathrm{~mm}$ in $\mathrm{RC}$ beam specimens.

Table 2 presents the test matrix of the RC beam specimens, in which two parameters were investigated:

(i) FRCM type: glass-, PBO-, and carbon-FRCM.

(ii) Strengthening configuration: the beam specimen was strengthened along the critical shear span either fully by a continuous FRCM plate or intermittently by a set of 120 $\mathrm{mm}$ wide FRCM strips spaced at $95 \mathrm{~mm}$.
The FRCM system was applied on each side of the strengthened beam and composed of (i) an internal mortar layer of $5 \mathrm{~mm}$ in thickness, placed after roughening the concrete surface; (ii) two layers of textile separated by a 3-mm thick intermediate mortar layer; and (iii) an external layer of 5-mm thick mortar.

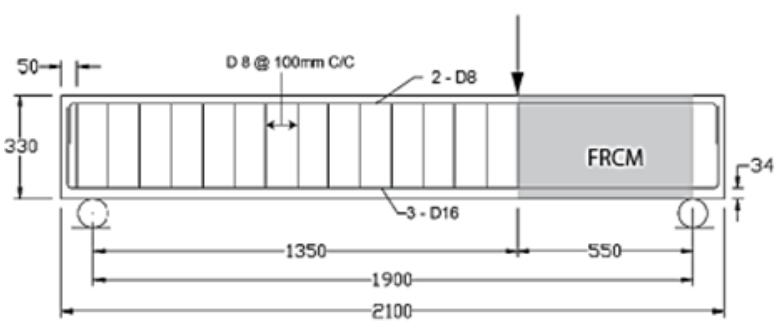

(a) Full-length FRCM strengthening

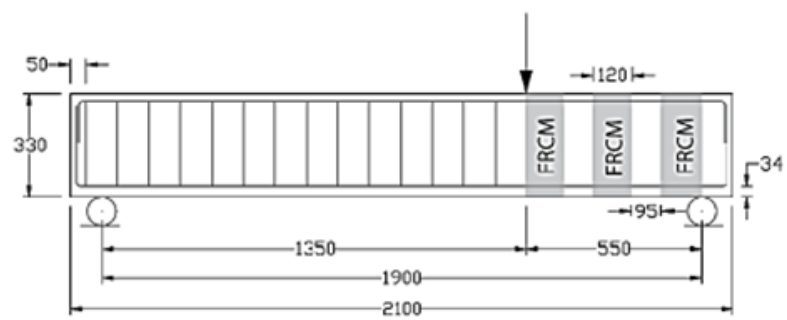

(b) Intermittent-vertical FRCM strengthening

Fig. 1. Elevations of the beam specimens with (a) full-length and (b) intermittent FRCM shear strengthening systems.

Table 2. Test matrix for the beam specimens.

\begin{tabular}{|c|c|c|}
\hline Beam ID & $\begin{array}{c}\text { Textile } \\
\text { material }\end{array}$ & $\begin{array}{c}\text { Strengthening } \\
\text { configuration }\end{array}$ \\
\hline Reference & - & - \\
\hline C-Full & Carbon & Full \\
\hline C-Intermittent & $\underline{\text { Carbon }}$ & Intermittent \\
\hline P-Full & $\underline{\text { PBO }}$ & Full \\
\hline P-Intermittent & $\underline{\text { PBO }}$ & Intermittent \\
\hline G-Full & $\underline{\text { Glass }}$ & Full \\
\hline G-Intermittent & $\underline{\text { Glass }}$ & Intermittent \\
\hline
\end{tabular}

\subsection{Test setup}

\subsubsection{Test setup for FRCM tensile characterization}

The tensile characterization test setup for FRCM coupons is illustrated in Figure 2. Tensile load was uniaxially applied at a rate of $0.25 \mathrm{~mm} / \mathrm{min}$. Metal plates were attached to the specimen's ends using epoxy with a 150$\mathrm{mm}$ bond length. The specimen was gripped by a double clevis-type connection from one end and a single clevistype connection from the other. A clip-type displacement transducer was placed to continuously measure the extension of the test coupon. Hence, the FRCM strain can be calculated as the measured coupon's extension divided by the 200-mm extensometer length.

For each load step, the axial tensile stress can be determined as the recorded load (P) divided by the FRCM equivalent area. This FRCM equivalent area is actually 
the average textile area per unit width $\left(\mathrm{A}_{\mathrm{f}}\right)$, provided in Table 1 for each textile type, multiplied by the specimen's width $(50 \mathrm{~mm})$.

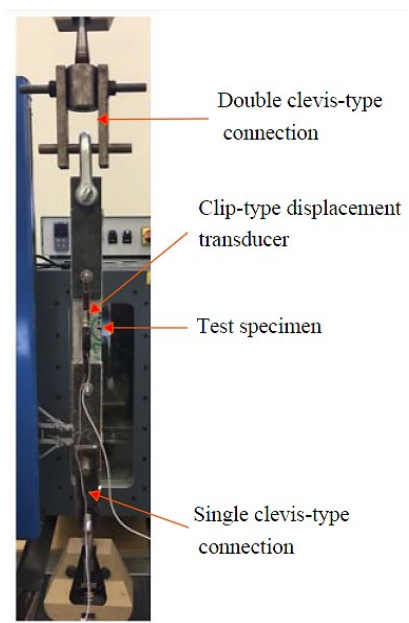

Fig. 2. Tensile characterization test setup.

\subsubsection{Test setup for RC beams}

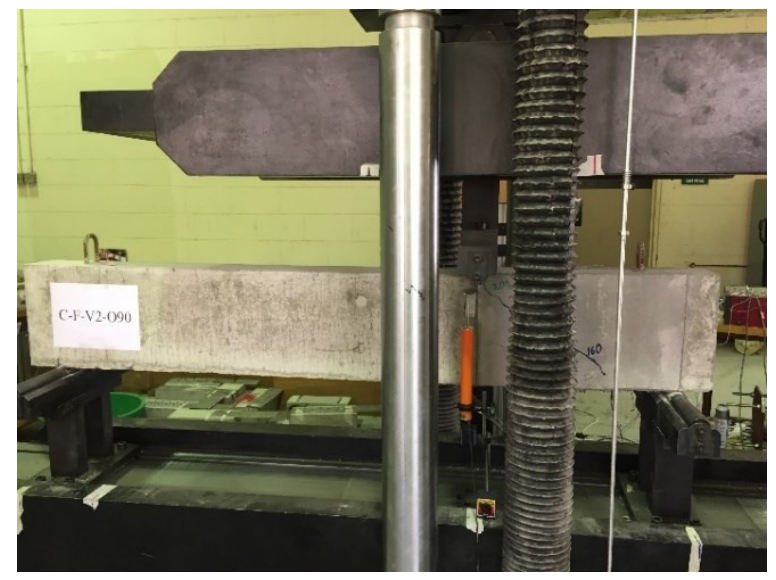

Fig. 3. Test setup for RC beams.

$\mathrm{RC}$ beams were tested under three-point loading (Figure 3 ) using the Instron 1500HDX Static Hydraulic Universal Testing machine located in Qatar University Structures Laboratory. Loading was applied on the tested beams at a rate of $1 \mathrm{~mm} / \mathrm{min}$ until failure. Strain gauges (with 5\% maximum limit and 5-mm gauge length) were fixed to the longitudinal bars. The deflection was measured below the loading point at each step using a linear variable displacement transducer. Data acquisition of the measurements was done at a $1-\mathrm{Hz}$ frequency range.

\section{Results and discussions}

\subsection{Tensile characterization test results}

Figure 4 shows a representative stress-strain diagram for each FRCM system. In general, the stress-strain diagram for a FRCM system is composed of two characteristic phases: (i) the prior-cracking stiff section phase represented by a steep curve; followed by (ii) a reduced- slope curve indicating the cracked section phase until failure. The initial stiffness of G-FRCM was observed to be lower than that of PBO-FRCM and C-FRCM. This can be attributed to the lower elastic modulus of glass textile as compared to that of PBO or carbon (Table 1).

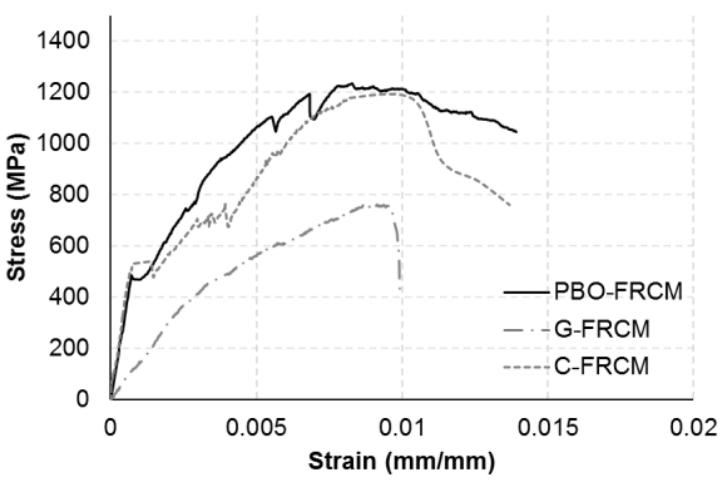

Fig. 4. Stress-strain diagrams for the FRCM systems adopted.

Table 3 lists the mean ultimate strain $\left(\varepsilon_{F R C M, u}\right)$, tensile strength $\left(\sigma_{F R C M, u}\right)$, cracked tensile modulus of elasticity $\left(E_{F R C M}\right)$, and failure mode for the FRCM coupons. To calculate $E_{F R C M}$ [28], a segment was considered between two data points at stress levels of $0.6 \sigma_{F R C M, u}$ and $0.9 \sigma_{F R C M, u}$ within the cracked-section curve. The slope of the line connecting these two points represents the cracked modulus of elasticity. The mean values of $E_{F R C M}$ for G-FRCM, PBO-FRCM, and C-FRCM are $60 \mathrm{GPa}$, $112 \mathrm{GPa}$, and $135 \mathrm{GPa}$, respectively.

Table 3. Summary of the tensile characterization test results.

\begin{tabular}{|c|c|c|c|c|}
\hline FRCM system & $\begin{array}{c}\sigma_{F R C M, u} \\
(\mathrm{MPa})\end{array}$ & $\begin{array}{c}\varepsilon_{F R C M, u} \\
(\%)\end{array}$ & $\begin{array}{c}E_{F R C M} \\
(\mathrm{GPa})\end{array}$ & $\begin{array}{c}\text { Failure } \\
\text { mode* }\end{array}$ \\
\hline G-FRCM & 767 & 0.93 & 60 & FR \\
\hline PBO-FRCM & 1235 & 1.06 & 112 & FS \\
\hline C-FRCM & 1178 & 1.04 & 135 & FS \\
\hline
\end{tabular}

${ }^{*}$ FS = Fabric Slippage; FR = Fabric Rupture

The G-FRCM system exhibited a more brittle failure behavior than that observed for the C-FRCM and PBOFRCM counterparts. This can be evidenced by the harsh drop in the stress-strain diagram of G-FRCM at failure (Figure 4). Such observation can be explained by the relatively lower tensile strength of the glass textile compared to that of PBO or carbon (Table 1), which in turn results in the premature rupture of the textile inside the G-FRCM coupons. On the other hand, the CarbonFRCM and PBO-FRCM systems generally showed a fabric-slippage type of failure. This explains the softening in the stress-strain curve after exceeding $\sigma_{F R C M, u}$.

All cracks were developed within the non-bonded area of the tensile coupons with no sign of slippage of the epoxy-bonded metal plates. The carbon-FRCM and PBOFRCM systems have generally shown a higher number of cracks than that of the glass-FRCM counterpart. This can be probably attributed to the lower loading capacity of the glass-FRCM coupon than that of the carbon-FRCM and PBO-FRCM counterparts. 


\subsection{RC beam test results}

Table 4 presents a summary of the test results for RC beam specimens. For each specimen, the second and the third columns of Table 4 list the ultimate load carrying capacity $\left(P_{u}\right)$ and the gain in $P_{u}$ as compared to that of the non-strengthened benchmark, respectively. As for the deformational characteristics, the deflection value $\left(\delta_{u}\right)$, the $\delta_{u} / \delta_{u, r e f}$ ratio, and the flexural strain $\left(\varepsilon_{s}\right)$ measured at failure are listed in the fourth, fifth, and sixth columns of Table 4, respectively.

Table 4. Summary of the RC beam test results.

\begin{tabular}{|c|c|c|c|c|c|}
\hline Beam ID & $\begin{array}{c}\boldsymbol{P}_{\boldsymbol{u}} \\
\mathbf{( k N )}\end{array}$ & $\begin{array}{c}\text { Gain } \\
\text { in } \\
\boldsymbol{P}_{\boldsymbol{u}} \\
\mathbf{( \% )}\end{array}$ & $\begin{array}{c}\boldsymbol{\delta}_{\boldsymbol{u}} \\
(\mathbf{m m})\end{array}$ & $\frac{\boldsymbol{\delta}_{\boldsymbol{u}}}{\boldsymbol{\delta}_{\boldsymbol{u}, \boldsymbol{r e f}}}$ & $\begin{array}{c}\boldsymbol{\varepsilon}_{\boldsymbol{s}, \boldsymbol{u}} \\
\mathbf{( \% )}\end{array}$ \\
\hline Reference & 104 & - & 3.25 & - & 0.143 \\
\hline C-Full & 210 & 101.6 & 7.75 & 2.14 & 0.286 \\
\hline C-Intermittent & 178 & 70.8 & 7.55 & 2.13 & 0.224 \\
\hline P-Full & 151 & 45.5 & 5.35 & 1.65 & 0.195 \\
\hline P-Intermittent & 138 & 32.4 & 4.6 & 1.42 & 0.170 \\
\hline G-Full & 168 & 61.4 & 6.10 & 1.88 & 0.197 \\
\hline G-Intermittent & 137 & 31.7 & 4.43 & 1.36 & 0.175 \\
\hline
\end{tabular}

\subsection{1 load carrying capacity}

In general, the ultimate load carrying capacity for the FRCM-strengthened beams was higher than that of the benchmark specimen, demonstrating the successful application of the FRCM strengthening systems to enhance the structural capacity of shear-critical RC beams. The average improvement of the load carrying capacity after shear-strengthening was 86.2, 39.0, 46.6\% for carbon, $\mathrm{PBO}$, and glass FRCM systems, respectively. Figures 5-(a), (b), and (c) show the load-deflection diagrams for the beam specimens strengthened with carbon-, PBO-, and glass-FRCM systems, respectively.

The carbon-FRCM strengthening system generally showed better improvement in $P_{u}$ than that of the PBOand Glass-FRCM systems. The RC beams with full-length strengthening configuration exhibited significantly higher enhancement in $P_{u}$ as compared to those with the intermittent strengthening configuration. This indicates the importance of the strengthening material's amount in the critical region. Furthermore, it was observed that using carbon-FRCM strengthening system was more effective in increasing the load carrying capacity of RC beams as compared to those with glass- and PBO-FRCM strengthening systems.
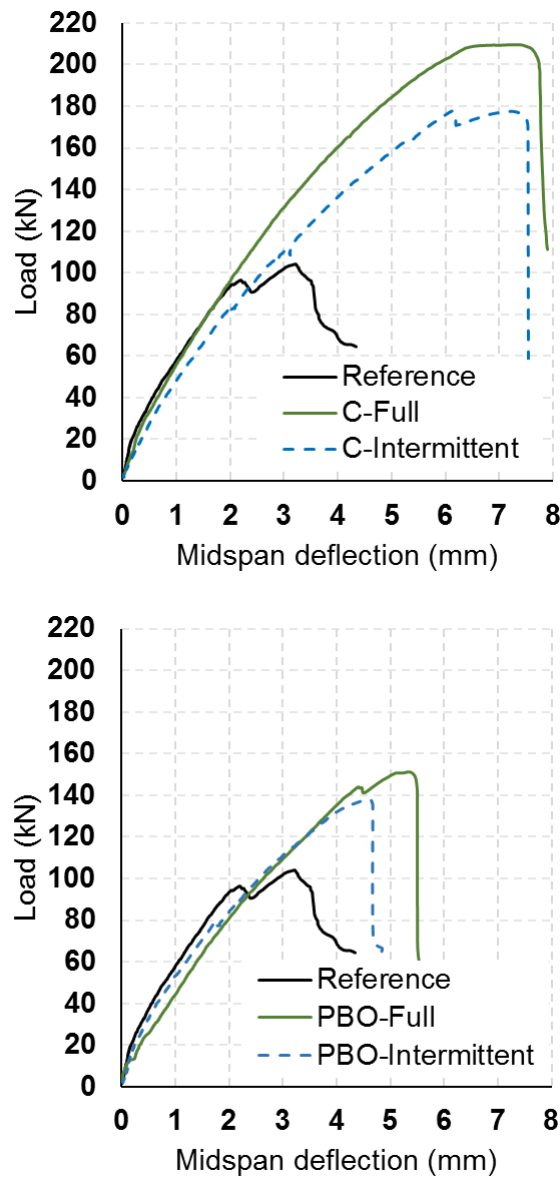

(a)

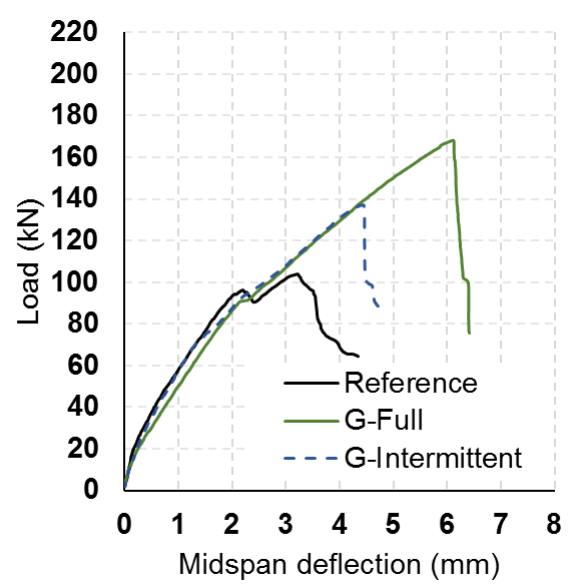

(b)

(c)

Fig. 5. Load-deflection plots for the beams with (a) CarbonFRCM, (b) PBO-FRCM, and (c) Glass-FRCM strengthening systems.

\subsubsection{Deformational characteristics}

In general, the deflection measured at failure $\left(\delta_{u}\right)$ for the strengthened beams was higher than that of the benchmark specimen $\left(\delta_{u, r e f}=3.25 \mathrm{~mm}\right)$. The beams strengthened with carbon-FRCM systems exhibited higher values of $\delta_{u}$ than those measured for Glass- and PBO-FRCM counterparts, which can be an indication to a superior structural performance for the beams strengthened with carbon-FRCM systems. As an example, the C-Full specimen has a $\delta_{u}$ value of $7.75 \mathrm{~mm}$, which is 
higher than those measured for P-Full $\left(\delta_{u}=5.35 \mathrm{~mm}\right)$ and G-Full $\left(\delta_{u}=6.10 \mathrm{~mm}\right)$ specimens. In addition, the specimens with full-length strengthening configuration showed slightly higher values of $\delta_{u}$ compared to those with the intermittent strengthening. For instance, the PIntermittent specimen has a $\delta_{u}$ value of $4.6 \mathrm{~mm}$, which is lower than that measured for P-Full specimen $\left(\delta_{u}=\right.$ $5.35 \mathrm{~mm}$ ).

With reference to the flexural strain, all beam specimens have failed prior to the yield of the main steel $\left(\varepsilon_{s, u}<\varepsilon_{y}=0.266 \%\right)$, with the exception of C-Full that has failed just after achieving the yield tensile strain $\left(\varepsilon_{s, u}=0.286 \%\right)$. The $\varepsilon_{s, u}$ value for the FRCMstrengthened beams was commonly higher than that of the benchmark specimen, indicating the successful application of the FRCM system in postponing the brittle shear failure and, to some extent, allowing the main steel to be a little closer to the yield region.

\section{Conclusions}

This paper has investigated the effectiveness of FRCM systems in shear-strengthening of reinforced concrete beams. Three FRCM systems were considered, namely, carbon-FRCM, glass-FRCM, and PBO-FRCM. In the first part of this paper, tensile characterization test was performed on 15 FRCM coupons to measure the uniaxial tensile properties of the adopted FRCM systems. In the second part of this effort, a total of $7 \mathrm{RC}$ beams were tested under three-point loading. Two test variables were considered, namely, the FRCM material and the strengthening configuration. Based on the study results, the following conclusions have been drawn:

- A typical shape was observed for the stress-strain diagrams of the FRCM tensile coupons with two distinct phases, of which the first is a steep curve indicating the non-cracked section, and the second is a gentle curve representing the cracked section.

- The cracked modulus of elasticity was calculated as 60 $\mathrm{GPa}, 112 \mathrm{GPa}$, and $135 \mathrm{GPa}$ for glass-FRCM, PBOFRCM, and carbon-FRCM, respectively.

- FRCM has been successfully used to improve the load carrying capacity of shear-critical RC beams. The average gain in the load carrying capacity achieved with FRCM-strengthening was $57 \%$.

- A better strength improvement was reported for the fulllength strengthening configuration than that of the intermittent counterpart.

- Carbon-FRCM systems were more effecient than PBOand glass-FRCM counterparts in improving the structural performance of RC beams.

This paper was made possible by NPRP grant \# NPRP 7-17202-641 from the Qatar National Research Fund (a member of Qatar Foundation). The findings achieved herein are solely the responsibility of the authors.

\section{References}

1. Younis, A.; Ebead, U. A.; Nanni, A. A Perspective on Seawater/FRP Reinforcement in Concrete
Structures. In Proceedings of the Ninth International Structural Engineering and Construction Conference, Resilient Structures and Sustainable Construction; ISEC Press: Valencia, Spain, 2017; p. St-38.

2. Ebead, U. Inexpensive Strengthening Technique for Partially Loaded Reinforced Concrete Beams : Experimental Study. Journal of materials in civil engineering 2015, 11, 1-11, doi:10.1061/(ASCE)MT.1943-5533.0001249.

3. Baky, H. A.; Ebead, U. A.; Neale, K. W. Flexural and interfacial behavior of FRP-strengthened reinforced concrete beams. Journal of Composites for Construction 2007, 11, 629-639.

4. Ebead, U. Hybrid externally bonded/mechanically fastened fiber-reinforced polymer for RC beam strengthening. ACI Structural Journal 2011, 108, 669.

5. Ebead, U.; Marzouk, H. Fiber-reinforced polymer strengthening of two-way slabs. ACI Structural Journal 2004, 101, 650-659.

6. Elsayed, W. E.; Ebead, U. A.; Neale, K. W. Mechanically fastened FRP-strengthened two-way concrete slabs with and without cutouts. Journal of Composites for Construction 2009, 13, 198-207.

7. Kotynia, R.; Abdel Baky, H.; Neale, K. W.; Ebead, U. A. Flexural strengthening of RC beams with externally bonded CFRP systems: Test results and 3D nonlinear FE analysis. Journal of Composites for Construction 2008, 12, 190-201.

8. Ebead, U. A.; Saeed, H. Flexural and Interfacial Behavior of Externally Bonded/Mechanically Fastened Fiber-Reinforced Polymer Strengthened Reinforced Concrete Beams. ACI Structural Journal 2014, 111, 741-752.

9. Awani, O.; El-Maaddawy, T.; Ismail, N. Fabricreinforced cementitious matrix: A promising strengthening technique for concrete structures. Construction and Building Materials 2017, 132, 94111.

10. Shrestha, K. C.; Ebead, U.; Younis, A. Effect of Surface Roughening on Concrete/FRCM Bond. In Proceedings of the Ninth International Structural Engineering and Construction Conference, Resilient Structures and Sustainable Construction; ISEC Press: Valencia, Spain, 2017; p. St-43.

11. Loreto, G.; Leardini, L.; Arboleda, D.; Nanni, A. Performance of RC slab-type elements strengthened with fabric-reinforced cementitious-matrix composites. Journal of Composites for Construction 2013, 18, A4013003.

12. Ombres, L.; Verre, S. Structural behaviour of fabric reinforced cementitious matrix (FRCM) strengthened concrete columns under eccentric loading. Composites Part B: Engineering 2015, 75, 235-249.

13. Colajanni, P.; Fossetti, M.; Macaluso, G. Effects of confinement level, cross-section shape and corner radius on the cyclic behavior of CFRCM confined concrete columns. Construction and Building Materials 2014, 55, 379-389.

14. Ombres, L. Concrete confinement with a cement based high strength composite material. Composite 
Structures 2014, 109, 294-304.

15. Ebead, U.; Shrestha, K. C.; Afzal, M. S.; El Refai, A.; Nanni, A. Effectiveness of fabric-reinforced cementitious matrix in strengthening reinforced concrete beams. Journal of Composites for Construction 2017, 21, 4016084.

16. Elghazy, M.; El Refai, A.; Ebead, U. A.; Nanni, A. Effect of corrosion damage on the flexural performance of RC beams strengthened with FRCM composites. Composite Structures 2017, 180, doi:10.1016/j.compstruct.2017.08.069.

17. Loreto, G.; Babaeidarabad, S.; Leardini, L.; Nanni, A. RC beams shear-strengthened with fabricreinforced-cementitious-matrix (FRCM) composite. International Journal of Advanced Structural Engineering (IJASE) 2015, 7, 341-352.

18. Younis, A.; Ebead, U.; Shrestha, K. C. Different FRCM systems for shear-strengthening of reinforced concrete beams. Construction and Building Materials 2017, 153, 514-526, doi:10.1016/j.conbuildmat.2017.07.132.

19. Wakjira, T. G.; Ebead, U. Hybrid NSE/EB technique for shear strengthening of reinforced concrete beams using FRCM: Experimental study. Construction and Building Materials 2018, 164, 164-177, doi:10.1016/j.conbuildmat.2017.12.224.

20. Younis, A.; Ebead, U. A.; Shrestha, K. C. FRCM Shear Strengthening for Concrete Beams. In Proceedings of the Ninth International Structural Engineering and Construction Conference, Resilient Structures and Sustainable Construction; ISEC Press: Valencia, Spain, 2017; p. St-27.
21. ACI Committee 549 Guide to design and construction of externally bonded fabric-reinforced cementitious matrix (FRCM) systems for repair and strengthening concrete and masonry structures (ACI 549.4R-13); American Concrete Institute: Farmington Hills, MI, USA., 2013; ISBN 9780870318528.

22. Younis, A.; Ebead, U. A.; Shrestha, K. C. Tensile Characterization of Textile Reinforced Mortar. In Proceedings of the Ninth International Structural Engineering and Construction Conference, Resilient Structures and Sustainable Construction; ISEC Press: Valencia, Spain, 2017; p. St-28.

23. Carozzi, F. G.; Poggi, C. Mechanical properties and debonding strength of Fabric Reinforced Cementitious Matrix (FRCM) systems for masonry strengthening. Composites Part B: Engineering 2015, 70, 215-230, doi:10.1016/j.compositesb.2014.10.056.

24. ISE/104 Committee BS 4449:2005: Steel for the reinforcement of concrete. Weldable reinforcing steel. Bar, coil and decoiled product; BSI, 2005; ISBN 9780580927157.

25. SIKA Technical datasheet, SikaWrap-350G Grid data sheet.; 2016;

26. Ruredil Technical datasheet, Ruredil X mesh C10 data sheet.; 2016;

27. Ruredil Technical datasheet, Ruredil X mesh gold data sheet.; 2016;

28. International Code Council Acceptance criteria for masonry and concrete strengthening using fabricreinforced cementitious matrix (FRCM) composite systems (AC434).; Washington, DC, 2013; 